\title{
EVALUATION OF COMMON MICROSCOPIC TECHNIQUES FOR DETECTION OF BLASTOCYSTIS HOMINIS
}

\section{By}

WAAD T. ALDAHHASI ${ }^{1}$, FAWZIA H. TOULAH ${ }^{1}$ and MAJED H. WAKID ${ }^{2,3^{*}}$

Department of Biology ${ }^{1}$, Faculty of Science, University of Jeddah, Jeddah, and Department of Medical Laboratory Technology ${ }^{2}$, Special Infectious Agent Unit, King Fahd Medical Research Center ${ }^{3}$, Faculty of Applied Medical Sciences, P. O. Box 80324, King Abdul Aziz University, Jeddah 21589,, Saudi Arabia ( ${ }^{*}$ Correspondence: E-mail: mwakid@kau.edu.sa, Fax: 009662-6952000 ext. 25502)

\section{Abstract}

Blastocystis hominis is the most prevalent eukaryotic intestinal protozoa that colonize the human gut, associated with intestinal disorders, with pathogenic controversial as most of them are asymptomatic. In this study, a comparison was carried out for sensitivity and specificity among two common using light microscopy, direct wet smear and Ritchie for the diagnosis $B$. hominis in human stools. Stool samples were collected from 29 Saudi and 111 non-Saudi patients, and examined for the detection of $B$. hominis. The infection was among age group between 31-50 years old and the highest rate was among male patients. Also, the results revealed that 98 samples were positive by direct smears; the sensitivity and specificity were $100 \%$ $\& 75.9 \%$ respectively. Meanwhile, Ritchie technique revealed 86 positive samples, the sensitivity and specificity were $99 \%$ and $90.9 \%$ respectively.

Key-words: Saudi Arabia, Blastocystis hominis, parasites, direct smears, Ritchie.

\section{Introduction}

B. hominis is anaerobic protozoan eukaryotic parasite, which was firstly classified as yeasts. Relying on the sequencing of the gene encoding the $18 \mathrm{~S}$ rRNA, $B$. hominis is now reclassified within the Stramenopiles group (Eme et al, 2017; Silberman et al, 1996). In human and a wide range of animals including birds, mammals and amphibians, nine subtypes of parasite were described (Andersen and Stensvold, 2016; Parkar et al, 2010). The prevalence ranged from $22 \%$ up to $100 \%$ in European, Asian \& African Countries (AbuOdeh et al, 2016; Krogsgaard et al, 2015; El Safadi et al, 2014). The prevalence depends on the geographical areas, sanitation facilities level, personal hygiene and accuracy of diagnostic methods (Sánchez et al, 2017; El-Marhoumy et al, 2015; Stensvold, 2013; Abdulsalam et al, 2012). Diagnosis is based on microscopic examination of stool samples by using wet smears, iodine or trichrome, staining smears and formal ether concentration method to increase the microscopic examination performance, as well as in-vitro short-term culture. Now, the modern molecular biological techniques as real-Time PCR have provided more sensi- tive and specific methods for B. hominis diagnosis (Stensvold et al, 2007; Dogruman-Al et al, 2010; Zhang et al, 2012; Taghipour et al, 2018; Kok et al, 2019). Generally, the transmission is feco-oral route of cysts (Popruk et al, 2015). Infection can be asymptomatic or mild abdominal discomfort, constipation, diarrhea, nausea, bloating, anorexia, irritable bowel syndrome, dehydration, pruritis Tan et al, 2010; Nagel et al, 2016; Ajjampur and Tan, 2016).

This study aimed to compare sensitivity and specificity among the common microscopic methods for detection of B. hominis.

\section{Materials and Methods}

Samples collection: 140 stool samples of Saudi and non-Saudi patients were collected from different hospitals in Makkah. All stool samples were collected using clean sterile containers, then; samples were kept in laboratory fridge at $4^{\circ} \mathrm{C}$ till further examinations.

Microscopic direct smears examination: $1-2 \mathrm{mg}$ for each stool sample was mixed in a drop of normal saline $\mathrm{NaCl} ; 0.9 \%$ (w/v) and Lugol's iodine on a microscope slide and each covered with a glass coverslip $(22 \times 22$ $\mathrm{mm}$ ), then examined by light microscope with 10x \& 40x lenses (Amer et al, 2016). 
Para-Pak ${ }^{\circledR}$ Trichrome stain (No. 400101): According to the manufacturer's instructions thin smears of polyvinyl alcohol (PVA)preserved stool samples were prepared, left overnight to fully dry, stained for 6-8 minutes in Trichrome stain and then transferred into acidified ethanol for 10 seconds. After beginning of staining, slides were dipped immediately for twice quick dips in ethanol (95\%), left for 5 minutes and finally in ethanol (96-100\%) for 3 minutes. Each slide was placed in xylene for 3 minutes and mounted using Canada balsam in xylene, and then covered by coverslip. Slides were examined under oil immersion of light microscope.

Ritchie sedimentation technique: About 2 gm from each sample was emulsified in 10 $\mathrm{ml}$ of formal-saline $(10 \%)$, and filtered via 2-3 gauze layers into a $15 \mathrm{ml}$ polypropylene tube. Tubes were centrifuged for 5 minutes at $2000 \mathrm{rpm}$. After discarding the supernatant, sediment was resuspended in a $10 \mathrm{ml}$ of $10 \%$ formal-saline, mixed thoroughly, then mixed with $3 \mathrm{ml}$ of diethyl ether and shake vigorously for 15 seconds then re-centrifuged at 2000rpm for 5 minutes. After centrifugation, the top of 3 layers were removed, and sediment was mixed with 2 drops of iodine. Microscopic examination was done by using 10x \& 40x (Wakid, 2009).

Statistical analysis: Chi-square or P-value was used to test correlation between methods, stool consistency, nationality, ages \& sex in relation to $B$. hominis. Kappa agreement was applied to validite diagnostic tests compared with the assumed gold standard test. Data were entered to the SPSS program (version 22). P value of $<0.05$ was defined as statistically significant.

Ethical approval was obtained from the Ministry of Health Makkah, Saudi Arabia.

\section{Results}

Out of 140 faecal samples, there were 98 infected cases. Six protozoan parasites were detected including 96 samples $B$. hominis, 8 Giardia lamblia, 6 Endolimax nana, 5 Entamoeba coli, 4 Entam oeba histolytica, and 1
Iodamoeba butschlii. Four helminthes were detected including 4 Ascaris lumbricoides, 3 for each of hookworms, and Hymenolepis nana and 2 Trichuris trichiura.

B. hominis infections were Saudi (20.71\%) and non-Saudi (79.29\%) patients, with higher rate among workers from Bangladeshi (37.5\%). There was significant relationships between nationality and ages with $B$. hominis using all techniques $(\mathrm{P}<0.05)$. Most patients were between 31-50 years old. A significant relationship was with six direct smears $(\mathrm{P}<0.05)$. Stool samples were soft $(77)$, loose (36), formed (21), hard (4), and watery (2) patients, without significant relationship between stool consistency and $B$. hominis infection by all techniques ( $\mathrm{P}>0.05)$.

$B$. hominis in relation to used techniques: Out of 140 samples screened for B. hominis, direct smears detected $96(68.6 \%)$ samples and Ritchie sedimentation 82 (58.6\%).

B. hominis and other parasites in different nationalities showed no significant correlation between nationality and parasites other than $B$. hominis by all techniques $(\mathrm{P}>0.05)$. Also, there was no statistical difference in detection of all parasites including $B$. hominis by different techniques $(\mathrm{P}>0.05)$. There was a significant relationship between nationality and $B$. hominis infection using all techniques $(\mathrm{P}<0.001)$.

Parasites of 98 samples were $75.51 \%$, $16.33 \%, 6.12 \%, 2.04 \%$ for single, double, triple and quadruple infection respectively.

Sensitivity and specificity: When direct smear was considered as a gold test, Ritchie technique showed $85.4 \%$ sensitivity \& $100 \%$ specificity. Ritchie technique gave equal accuracy of $90 \%$ and diagnostic test agreement (Kappa test) 0.786. When Ritchie technique was considered as a nominated gold test, direct wet smear equal accuracy $90 \%$, sensitivity $100 \%$, specificity $75.9 \%$ and test agreement (Kappa test) 0.786 .

The details were given in tables $(1,2,3$ \& 4). 
Table 1: Infection with $B$. hominis and other parasites in relation to nationality groups using all techniques

\begin{tabular}{|c|c|c|c|c|c|c|}
\hline \multirow{2}{*}{\multicolumn{2}{|c|}{ Parasite }} & \multirow{2}{*}{ Techniques } & Non-Saudi $(\mathrm{N}=111)$ & Saudi $(N=29)$ & Total $(n=140)$ & \multirow{2}{*}{$\mathrm{P}$-value ${ }^{b}$} \\
\hline & & & No. $(\%)$ & No. $(\%)$ & No. $(\%)$ & \\
\hline \multirow{18}{*}{$\begin{array}{l}\text { 尺̊ } \\
\text { N } \\
0 \\
0 \\
0\end{array}$} & \multirow{3}{*}{ B. hominis } & Direct smears & $89(80.2)$ & $7(24.1)$ & $96(68.6)$ & $<0.001$ \\
\hline & & Ritchie technique & $78(70.3)$ & $4(13.8)$ & $82(58.6)$ & $<0.001$ \\
\hline & & P-value ${ }^{\mathrm{a}}$ & \multicolumn{4}{|c|}{$>0.05$} \\
\hline & \multirow{3}{*}{ E. histolytica } & Direct smears & $2(1.8)$ & $0(0.0)$ & $2(1.4)$ & $>0.05$ \\
\hline & & Ritchie technique & $4(3.6)$ & $0(0.0)$ & $4(2.9)$ & $>0.05$ \\
\hline & & P-value ${ }^{a}$ & \multicolumn{4}{|c|}{$>0.05$} \\
\hline & \multirow{3}{*}{ E. coli } & Direct smears & $4(3.6)$ & $1(3.4)$ & $5(3.6)$ & $>0.05$ \\
\hline & & Ritchie technique & $4(3.6)$ & $1(3.4)$ & $5(3.6)$ & $>0.05$ \\
\hline & & P-value ${ }^{\mathrm{a}}$ & \multicolumn{4}{|c|}{$>0.05$} \\
\hline & \multirow{3}{*}{ E. nana } & Direct smears & $5(4.5)$ & $1(3.4)$ & $6(4.3)$ & $>0.05$ \\
\hline & & Ritchie technique & $4(3.6)$ & $1(3.4)$ & $5(3.6)$ & $>0.05$ \\
\hline & & P-value ${ }^{a}$ & \multicolumn{4}{|c|}{$>0.05$} \\
\hline & \multirow{3}{*}{ I. butschlii } & Direct smears & $1(0.9)$ & $0(0.0)$ & $1(0.7)$ & $>0.05$ \\
\hline & & Ritchie technique & $0(0.0)$ & $0(0.0)$ & $0(0.0)$ & - \\
\hline & & P-value ${ }^{\mathrm{a}}$ & \multicolumn{4}{|c|}{$>0.05$} \\
\hline & \multirow{3}{*}{ G. lamblia } & Direct smears & $8(7.2)$ & $0(0.0)$ & $8(5.7)$ & $>0.05$ \\
\hline & & Ritchie technique & $7(6.3)$ & $0(0.0)$ & $7(5.0)$ & $>0.05$ \\
\hline & & P-value ${ }^{a}$ & \multicolumn{4}{|c|}{$>0.05$} \\
\hline \multirow{12}{*}{ 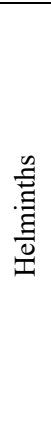 } & \multirow{3}{*}{ Hookworm } & Direct smears & $1(0.9)$ & $0(0.0)$ & $1(0.7)$ & $>0.05$ \\
\hline & & Ritchie technique & $3(2.7)$ & $0(0.0)$ & $3(2.1)$ & $>0.05$ \\
\hline & & P-value ${ }^{\mathrm{a}}$ & \multicolumn{4}{|c|}{$>0.05$} \\
\hline & \multirow{3}{*}{ T. trichiura } & Direct smears & $1(0.9)$ & $0(0.0)$ & $1(0.7)$ & $>0.05$ \\
\hline & & Ritchie technique & $2(1.8)$ & $0(0.0)$ & $2(1.4)$ & $>0.05$ \\
\hline & & P-value ${ }^{\mathrm{a}}$ & \multicolumn{4}{|c|}{$>0.05$} \\
\hline & \multirow{3}{*}{$\begin{array}{l}\text { A. lumbri- } \\
\text { coides }\end{array}$} & Direct smears & $3(2.7)$ & $0(0.0)$ & $3(2.1)$ & $>0.05$ \\
\hline & & Ritchie technique & $4(3.6)$ & $0(0.0)$ & $4(2.9)$ & $>0.05$ \\
\hline & & P-value ${ }^{\mathrm{a}}$ & \multicolumn{4}{|c|}{$>0.05$} \\
\hline & \multirow{3}{*}{ H. nana } & Direct smears & $1(0.9)$ & $0(0.0)$ & $1(0.7)$ & $>0.05$ \\
\hline & & Ritchie technique & $3(2.7)$ & $0(0.0)$ & $3(2.1)$ & $>0.05$ \\
\hline & & P-value ${ }^{\mathrm{a}}$ & \multicolumn{4}{|c|}{$>0.05$} \\
\hline
\end{tabular}

a: $\mathrm{P}$-value in relation to type of technique, $\mathrm{b}$ : P-value in relation to nationality

Table 2: Types of infection and detected parasites using microscopy techniques.

\begin{tabular}{|c|c|c|}
\hline $\begin{array}{l}\text { Infection } \\
\text { No. }(\%)\end{array}$ & Parasites (+ve) & Nationality N. \\
\hline \multirow[t]{2}{*}{$\begin{array}{c}\text { Single } \\
74(75.51)\end{array}$} & B. hominis (72) & $\begin{array}{l}\text { Bangladeshi 29, Egyptian 1, Ghanaian 1, } \\
\text { Indian } 8 \text { Indonesian 2, Jordanian 1, Moroc- } \\
\text { can 1, Pakistani 2, Palestinian 12, Filipinos } \\
\text { 5, Saudi } 6 \text {, Sudanese 1, Syrian 1, Vietnam- } \\
\text { ese } 1 \& \text { Yemeni } 1\end{array}$ \\
\hline & A. lumbricoides (2) & Bangladeshi 2 \\
\hline \multirow{7}{*}{$\begin{array}{c}\text { Double } \\
16(16.33)\end{array}$} & B. hominis + E. nana (4) & Bangladeshi 2, Egyptian 1, Pakistani 1 \\
\hline & B. hominis + E. coli $(2)$ & Bangladeshi 1, Palestinian 1 \\
\hline & B. hominis + A. lumbricoides (1) & Palestinian 1 \\
\hline & B. hominis + hookworm (1) & Palestinian 1 \\
\hline & B. hominis + H. nana $(1)$ & Indian 1 \\
\hline & B. hominis + G. lamblia (6) & Bangladeshi 3, Indian 1, Palestinian 2 \\
\hline & B. hominis + E. histolytica $(1)$ & Indian 1 \\
\hline \multirow{5}{*}{$\begin{array}{l}\text { Triple } \\
6(6.12)\end{array}$} & B. hominis + E. nana + E. coli $(1)$ & Saudi 1 \\
\hline & B. hominis + T. trichiura +hookworm (1) & Sudanese 1 \\
\hline & B. hominis + E. coli + E. histolytica $(1)$ & Palestinian 1 \\
\hline & B. hominis + H. nana + G. lamblia $(2)$ & Filipinos 1, Pakistani 1 \\
\hline & B. hominis + E. histolytica + I. butschlii $(1)$ & Pakistani 1 \\
\hline \multirow{2}{*}{$\begin{array}{l}\text { Quadruple } \\
2(2.04 \%) \\
\end{array}$} & B. hominis + T. trichiura + hookworm + A. lumbricoides $(1)$ & Bangladeshi 1 \\
\hline & B. hominis + E. nana + E. coli + E. histolytica $(1)$ & Indian 1 \\
\hline Total & 98 & \\
\hline
\end{tabular}


Table 3: Detection of B. hominis in relation to different categories using all techniques.

\begin{tabular}{|c|c|c|c|c|c|c|}
\hline \multirow{2}{*}{\multicolumn{2}{|c|}{ Categories }} & \multirow{3}{*}{$\begin{array}{c}\text { No. } \\
46\end{array}$} & \multicolumn{2}{|c|}{ Direct smears } & \multicolumn{2}{|c|}{ Ritchie technique } \\
\hline & & & & & & \\
\hline Nationality & Bangladeshi & & $\frac{\text { No. }(\%)^{\mathrm{a}}}{36(37.5)}$ & $\begin{array}{l}\%^{b} \\
78.3\end{array}$ & $\frac{\text { No. }(\%)^{a}}{33(40.2)}$ & $\frac{\%^{b}}{71.7}$ \\
\hline & Egyptian & 2 & $2(2.1)$ & 100 & $2(2.4)$ & 100 \\
\hline & Ghanaian & 1 & $1(1.0)$ & 100 & $1(1.2)$ & 100 \\
\hline & Indian & 18 & $12(12.5)$ & 66.7 & $8(9.8)$ & 44.4 \\
\hline & Indonesian & 3 & $2(2.1)$ & 66.7 & $1(1.2)$ & 33.3 \\
\hline & Jordanian & 1 & $1(1.0)$ & 100 & $1(1.2)$ & 100 \\
\hline & Moroccan & 1 & $1(1.0)$ & 100 & $0(0.0)$ & 0.0 \\
\hline & Pakistani & 5 & $5(5.2)$ & 100 & $4(4.9)$ & 80.0 \\
\hline & Palestinian & 18 & $18(18.8)$ & 100 & $17(20.7)$ & 94.4 \\
\hline & Filipinos & 8 & $6(6.3)$ & 75.0 & $6(7.3)$ & 75.0 \\
\hline & Saudi & 29 & $7(7.3)$ & 24.1 & $4(4.9)$ & 13.8 \\
\hline & Sudanese & 2 & $2(2.1)$ & 100 & $2(2.4)$ & 100 \\
\hline & Syrian & 2 & $1(1.0)$ & 50.0 & $1(1.2)$ & 50.0 \\
\hline & Vietnamese & 1 & $1(1.0)$ & 100 & $1(1.2)$ & 100 \\
\hline & Yemeni & 3 & $1(1.0)$ & 33.3 & $1(1.2)$ & 33.3 \\
\hline & Total & 140 & $96(100)$ & & $82(100)$ & \\
\hline & $\chi^{2}$ & & \multicolumn{2}{|c|}{45.017} & \multicolumn{2}{|c|}{48.113} \\
\hline & P-value & & \multicolumn{2}{|c|}{$<0.001$} & \multicolumn{2}{|c|}{$<0.001$} \\
\hline \multirow[t]{6}{*}{ Age groups } & $<30$ & 35 & $35(36.5)$ & 66.0 & $30(36.6)$ & 56.6 \\
\hline & $31-50$ & 72 & $55(57.3)$ & 76.4 & $46(56.1)$ & 63.9 \\
\hline & $>50$ & 15 & $6(6.3)$ & 40.0 & $6(7.3)$ & 40.0 \\
\hline & Total & 140 & $96(100)$ & & $82(100)$ & \\
\hline & $\chi^{2}$ & & \multicolumn{2}{|c|}{7.881} & \multicolumn{2}{|c|}{3.056} \\
\hline & P-value & & \multicolumn{2}{|c|}{0.019} & \multicolumn{2}{|c|}{0.217} \\
\hline \multirow[t]{5}{*}{ Sex } & Female & 35 & $19(19.8)$ & 54.3 & $16(19.5)$ & 45.7 \\
\hline & Male & 105 & $77(80.2)$ & 73.3 & $66(80.5)$ & 62.9 \\
\hline & Total & 140 & $96(100)$ & & $82(100)$ & \\
\hline & $\chi^{2}$ & & \multicolumn{2}{|c|}{4.419} & \multicolumn{2}{|c|}{3.179} \\
\hline & $\mathrm{P}$-value & & \multicolumn{2}{|c|}{0.036} & \multicolumn{2}{|c|}{0.075} \\
\hline \multirow[t]{8}{*}{ Consistency } & Formed & 21 & $13(13.5)$ & 61.9 & $11(13.4)$ & 52.4 \\
\hline & Hard & 4 & $2(2.1)$ & 50.0 & $2(2.4)$ & 50.0 \\
\hline & Loose & 36 & $24(25.0)$ & 66.7 & $20(24.4)$ & 55.6 \\
\hline & Soft & 77 & $55(57.3)$ & 71.4 & $47(57.3)$ & 61.0 \\
\hline & Watery & 2 & $2(2.1)$ & 100 & $2(2.4)$ & 100 \\
\hline & Total & 140 & $96(100)$ & & $82(100)$ & \\
\hline & $\chi^{2}$ & & \multicolumn{2}{|c|}{2.342} & \multicolumn{2}{|c|}{2.196} \\
\hline & P-value & & \multicolumn{2}{|c|}{0.673} & 0.7 & \\
\hline
\end{tabular}

Table 4: Sensitivity, specificity and accuracy of diagnostic techniques

\begin{tabular}{|c|c|c|c|c|c|c|c|c|c|c|}
\hline \multicolumn{2}{|c|}{ Techniques } & $\mathrm{P}$ & $\mathrm{N}$ & $\begin{array}{c}\text { Sensitivity } \\
\%\end{array}$ & $\begin{array}{c}\text { Specificity } \\
\%\end{array}$ & $\begin{array}{c}\text { PPV } \\
\% \\
\end{array}$ & $\begin{array}{c}\text { NPV } \\
\% \\
\end{array}$ & $\begin{array}{c}\text { Accuracy } \\
\% \\
\end{array}$ & Kappa Test & P-value \\
\hline \multicolumn{11}{|c|}{ Direct smears* } \\
\hline \multirow{2}{*}{ Ritchie } & $\mathrm{P}$ & ${ }^{\mathrm{TP}} 82$ & ${ }^{\mathrm{FP}} 0$ & \multirow{2}{*}{85.4} & \multirow{2}{*}{100} & \multirow{2}{*}{100} & \multirow{2}{*}{75.9} & \multirow{2}{*}{90} & \multirow{2}{*}{$\begin{array}{c}0.786 \text { Substantial } \\
\text { agreement }\end{array}$} & \multirow[b]{2}{*}{$\mathrm{P}<0.001$} \\
\hline & $\mathrm{N}$ & $\mathrm{FN}_{14}$ & ${ }^{\mathrm{TN}} 44$ & & & & & & & \\
\hline \multicolumn{10}{|c|}{ Ritchie* } & \\
\hline \multirow{2}{*}{$\begin{array}{l}\text { Direct } \\
\text { smears }\end{array}$} & $\mathrm{P}$ & ${ }^{\mathrm{TP}} 82$ & ${ }^{\mathrm{FP}} 14$ & \multirow{2}{*}{100} & \multirow{2}{*}{75.9} & \multirow{2}{*}{85.4} & \multirow{2}{*}{100} & \multirow{2}{*}{90} & \multirow{2}{*}{$\begin{array}{c}0.786 \text { Substantial } \\
\text { agreement }\end{array}$} & \multirow[b]{2}{*}{$\mathrm{P}<0.001$} \\
\hline & $\mathrm{N}$ & ${ }^{\mathrm{FN}} 0$ & $\mathrm{TN}_{44}$ & & & & & & & \\
\hline
\end{tabular}

P: Positive N: Negative, FP: False positive TP: True positive, FN: False negative TN: True negative, *when considered gold standard method, PPV: positive predictive value NPV: negative predictive values

\section{Discussion}

In routine laboratory, the common techniques depend on microscopic examination using iodine Lugol's, sedimentation and trichrome staining (Adiyaman et al, 2015; van Lieshout and Roestenberg, 2015). In the present study trichrome stain was used with all protozoa positive cases. The consistency of stool samples ranged between formed to watery. Highest infection rate with $B$. hominis was in soft and loose stool (55\% \& $25.71 \%)$. This agreed with Das et al. (2013) in Bangladesh. In Iraq, patients' stools with B. hominis were liquid or semi-liquid stool played important role in case of persistence diarrhea in patients (Salman, 2015). This occurred 
mainly with large numbers of this protozoan in stools (Al-Kaissi and Al Magdi, 2009).

Prevalence of $B$. hominis among males using direct smears and Ritchie were 73.3\% \& $62.9 \%$, respectively. While in female patients were $54.3 \% \& 45.7 \%$, res- pectively. There was a significant difference when direct smears $(\mathrm{P}>0.05)$, was used. Nearly, the same data were obtained from patients in France and Egypt as the infection rate in males was higher than females (El Safadi et al, 2016; Hamdy et al, 2019). This may be due to the nature of males work in several fields ibut, females mainly work in houses.

The $B$. hominis highest infection rate was among patients aged from 31 to 50 years old. Also, patients aged 30 or below showed a higher infection rate than those above 50 years old. In Iran, $B$. hominis infection rate was more prevalent in ages between (40-49) years old (Khademvatan et al, 2018). In Iraq, B. hominis infection rates among patients with gastrointestinal disorders were high in elder age group (61 to 80) years old (Hammood et al, 2016). In Brazil, affected children aged 5-9 years (Segui et al, 2018). This discrepancy in B. hominis infection among different ages referred to outcome of the different risk or hazardous activities among each group (Mohammad et al, 2017).

In the present study, the single infection was detected in 74 samples (72 with B. hominis and 2 with $A$. lumbricoides) and B. hominis co-infection of with other parasites was in 24 samples. Pagheh et al. (2018) in Iran showed the co-infection of $B$. hominis with other intestinal parasites mainly protozoa).

Generally, the present results showed that protozoan infections $(85.71 \%)$ were higher than helminthic ones $(8.57 \%)$. Similar result was reported (Barbosa et al, 2018; Oishi et $a l, 2019)$. This may be due to the direct mode of intestinal protozoan transmission. Also, their life cycle is simpler than the helminthic complicated ones that need one or more intermediate host taking much time to form infective stage (Maizels et al, 1993).

The present study results revealed that the foreigner workers with highest intestinal parasites rates were Asians, mainly from Bangladesh, Palestine and India. A study on migrant workers in Malaysia found, the majority of infected workers were from Indonesia: 43.3\%, Nepal: 20.9\%, Bangladesh: 18\%, India: $12.1 \%$ \& Myanmar: 5.9.2\% (Sahimin et al, 2016). In Al-Baha, higher intestinal parasites were among Indonesians (41.42\%), Indians (22.89\%), Bangladeshis (10.93\%), Filipinos $(8.89 \%)$, Pakistanis $(9.71 \%)$, SriLankans (5.09), then Egyptians and Syrians (2.03\%) (Mohammad and Koshak, 2011). In Al-Khobar, intestinal parasites were more among workers Sri Lankans (44.8\%), Indonesians (28\%), Filipinos (18\%) and then Indians (8.6\%) (Abahussain and Abahussain, 2005). Also, in Sharjah, the highest infection rates were among Indian workers $(30.4 \%)$, Bangladeshis (20.6\%), Pakistanis (16.1\%) and Afghan (11.9\%) (Dafalla et al, 2017). Infection was B. hominis $(68.6 \%)$ followed by $G$. lamblia $(5.7 \%)$ then E. histolytica $(2.9 \%)$, which agreed with (Pestehchian et $a l, 2015)$ in Iran.

In the present study, high $G$. lamblia was among Bangladeshis (37.5\%), but, E. histolytica was among Indians (50\%) and $E$. coli among Palestinians (40\%). A study in India, showed the following infection rates: $G$. lamblia (69.5\%), and E. histolytica $(15.7 \%)$ (Yogyata and Binita, 2011). Taha et al. (2013) in Al-Madinah reported that the protozoa infection was $21.9 \%$ with $G$. lamblia and $17.8 \%$ with E. histolytica/ E. coli. E. histolytica among Sudanese workers was $37.1 \%$ and for Pakistani ones, the commonest was G. lamblia (34.14\%). Imam et al. (2015) in Al-Madinah detected E. histolytica in 19 cases $(27.5 \%)$, G. lamblia in 13 cases (18.8\%), and E. coli in 5 cases (7.2\%).

In the present study, E. nana was the common protozoa $(4.3 \%)$, followed by $E$. coli (3.6\%), \& I. butschlii (0.7\%). In Riyadh City, the protozoa were E. coli, I. butschlii \& E. nana $(4.08 \%, 1.79 \%$ \& $1.75 \%)$ respectively (Eligail et al, 2010). But, total nonpathogenic parasites were similar as being 
transmitted by oral fecal contamination, coinfected with pathogens (Poulsen and Stensvold, 2016).

Among non-Saudis (Bangladeshi \& Palestinian workers) were $A$. lumbricoides with highest infection rate $(2.8 \%), T$. trichiura i $(1.4 \%)$ was among a Sudanese and similarly in a Bangladeshi worker. Hookworm was found in a Palestinian, a Sudanese, and a Bangladeshi worker. But, H. nana was found in an Indians, a Filipino and a Pakistani worker. Al-Madinah study showed that T. trichiura was the commonest worms among those from Philippines, Sri Lanka and Indonesia with rate of $38.5 \%, 33.3 \% \& 31.8 \%$ respectively, followed by $A$. lumbricoides in Filipinos \& Indonesians (30.76\% \& 23.1\%). None of Bangladeshi workers was infected with helminthes. In Al-Madinah, the high rate was among Ethiopians followed by Indians and then Sri Lankans. In Ethiopians hookworm was $15.8 \%$ and T. trichiura and A. lumbricoides were lower $(0.3 \%$ \& $7.9 \%)$, respectively (Imam et al, 2015).

The non-Saudi patients were from Asian (75\%) and African countries (4.28\%). Most of them were infected with $B$. hominis $(68.6 \%$ \& $58.6 \%)$ by using direct smears and Ritchie technique respectively. Same findings were reported in Makkah during Hajj, as most of foreign workers were from Asia (Wakid, 2009). Also, in Makkah B. hominis was (59.8\%) among Asians (Ahmed et al, 2015). In Qatar Asian workers showed $87.6 \%$ B. hominis rate (Behnke, 2013), but $68.6 \%, 67.6 \%$ were from Western and Eastern Asia respectively (Abu-Madi et al, 2015). Lu and Sung (2009) in Taiwan found that $B$. hominis was among immigrant Indonesians, Vietnamese, Filipinos \& Chine se (26.4\% 20.6\%, 19.3\%\& 7.6\%) respectively.

By microscopy, B. hominis was $68.6 \%$. Bangladeshis showed the high infection rate $(37.5 \%)$, but one was among Ghanaians, Jordanians, Moroccans, Syrians, Vietnamese and Yemenis (1\% each). Ritchie's data were lower than direct smears (58.6\%). Ritchie technique is used mainly to detect cysts, ova and larvae, but not trophozoites (Srichaipon et al, 2019). Destruction or distortion of parasites during Ritchie's preparation gave false results (Wakid et al, 2009). Using Ritchie technique as gold standard method, microscopy sensitivity was $100 \%$ \& specificity was $75.9 \%$. In Iraq, microscopy sensitivity was $(74.14 \%) \&$ specificity was $100 \%$ (Uobeed et al, 2015). Using direct smears as gold standard method, sensitivity and specificity for Ritchie technique were $85.4 \%$ \& $100 \%$, respectively.

\section{Conclusions}

Periodically examination for intestinal parasites is a must for hand-workers by different diagnostic methods. Comparing microscopic and molecular techniques to detect $B$. hominis is ongoing and will be published in due time. To authors' knowledge none used direct smears as a gold standard method.

\section{Acknowledgements}

The authors are gratefully to the Staff of King Fahd Medical Research Centre, especially the Special Infectious Agents Unit. Also, sincere thanks also extend to the specialist and technicians for kind cooperation.

\section{References}

Abahussain, NA, Abahussain, N, 2005: Prevalence of intestinal parasites among expatriate workers in Al-Khobar, Saudi Arabia. Middle East J. Fam. Med. 3, 3:17-21.

Abdulsalam, AM, Ithoi, I, Al-Mekhlafi, HM, et al, 2012: Drinking water is a significant predictor of Blastocystis infection among rural Malaysian primary schoolchildren. Parasitol. 139, 8: 1014-20.

Abu-Madi, M, Aly, M, Behnke, J, et al, 2015: The distribution of Blastocystis subtypes in isolAtes from Qatar. Parasit. Vectors 8:465.

Abu-Odeh, R, Ezzedine, S, Samie, A, et al, 2016: Prevalence and subtype distribution of $B l$ astocystis in healthy individuals in Sharjah, United Arab Emirates. Infect. Gen. Evol. 37:158-62

Adıyaman, G, Al Doğruman, F, Mumcuoğlu, I, 2015: Investigation of the presence of Blastocystis spp. in stool samples with microscopic, culture and molecular methods. Mikrobiyoloji Bul. 49,1:85-97.

Ahmed, MA, Alam-Eldin, YH, Eltaweel, NA, et al, 2015: Intestinal parasites detected during 
pre-employment stool examination at tertiary health care center in Makkah, Kingdom of Saudi Arabia. J. Egypt. Soc. Parasitol. 45,2:367-73.

Ajjampur, SSR, Tan, KSW, 2016: Pathogenic mechanisms in Blastocystis spp. Interpreting results from in vitro and in vivo studies. Parasitol. Int. 65, 6:772-9.

Al-kaissi, E, Al Magdi, K, 2009: Pathogenicity of Blastocystis hominis in relation to entropathogens in gastroenteritis cases in Baghdad. Eur. J. Sci. Res. 25:606-13.

Amer, O, Ashankyty, IM, Haouas, NAS, 2016: Prevalence of intestinal parasite infections among patients in local public hospitals of Hail, Northwestern Saudi Arabia. Asian Pac. J. Trop. Med. 9,1:44-8.

Andersen, LO, Stensvold, CR 2016: Blastocystis in health and disease: are we moving from a clinical to a public health perspective?. J. Clin. Microbiol. 54,3:524-8.

Barbosa, CV, Barreto, MM, Andrade, RJ, et al, 2018: Intestinal parasite infections in a rural community of Rio de Janeiro (Brazil): Prevalence and genetic diversity of Blastocystis subtypes. PLoS. One 13, 3:e0193860.

Behnke, J, 2013: Dynamic trends in intestinal parasitic infections among recently arrived immigrant workers, settled immigrants and long-term residents in Qatar. Qatar Found. Ann. Res. Conf. Proc.

Dafalla, AIA, Almuhairi, SASO, AlHosani, M HJ, et al, 2017: Intestinal parasitic infections among expatriate workers in various occupations in Sharjah, United Arab Emirates. Rev. Inst. Med. Trop. Sao. Paulo 59,e82:1-7.

Das, KF, Faruque, ASG, Chisti, MJ, et al, 2013: Comparison of stool microscopy between young and elderly adults without diarrhea in rural Bangladesh. J. Hlth. Med. Infor. 4, 1:116-20. Dogruman-Al, F, Simsek, Z, Boorom, K, et al, 2010: Comparison of methods for detection of Blastocystis infection in routinely submitted stool samples, and also in IBS/IBD patients in Ankara, Turkey. PLoS One 5, 1:1.

El-Safadi, D, Gaayeb, L, Meloni, D, et al, 2014: Children of senegal river basin show the highest prevalence of Blastocystis sp. ever observed worldwide. BMC Infect. Dis. 14, 1:164-75. El-Safadi, D, Cian, A, Nourrisson, C, et al, 2016: Prevalence, risk factors for infection and subtype distribution of the intestinal parasite Blastocystis $s p$. from a large-scale multi-center study in France. BMC Infect. Dis. 16,1:451-62.
El-Marhoumy, SM, El-Nouby, KA, Shoheib, ZS, et al, 2015: Prevalence and diagnostic approach for a neglected protozoon Blastocystis hominis. Asian Pac. J. Trop. Dis. 5,1:51-9.

Eligail, AM, Masawi, AM, Al-Jaser, NM, et al, 2010: Audit of stool analysis results to ensure the prevalence of common types of intestinal parasites in Riyadh region, Saudi Arabia. Saudi J. Biol. Sci. 17, 1:1-4.

Eme, L, Gentekaki, E, Curtis, B, et al, 2017: Lateral gene transfer in the adaptation of the anaerobic parasite Blastocystis to the Gut. Curr. Biol. 27, 6:807-21.

Hamdy, DA, Abd El Wahab, WM, Senosy, S A, et al, 2019: Blastocystis spp. and Giardia intestinalis co-infection profile in children suffering from acute diarrhea. J. Parasit. Dis. 19:1-11.

Hammood, AM, Ahmed, BA, Salman, YJ, 2016: Blastocystis hominis detection among gastrointestinal disorders' patients in Kirkuk province using three different laboratory methods. Int. J. Curr. Microbiol. Appl. Sci. 5,7:883-900.

Imam, NF, Abdulbaqi, ZB, Fahad, RA, 2015: The prevalence of intestinal parasitic infections among foreign workers in Madinah, Kingdom of Saudi Arabia. Saudi J. Med. Sci. 3, 2: 112-7.

Khademvatan, S, Masjedizadeh, R, Yousefirazin, E, et al, 2018: PCR-based molecular characterization of Blastocystis hominis subtypes in southwest Iran. J. Infect. Publ. Hlth. 11, 1:43-7. Kok, M, Cekin, Y, Cekin, AH, et al, 2019: Ro le of Blastocystis hominis in activation of ulcerative colitis. Turk. J. Gastroenterol. 30, 1: 40-6.

Krogsgaard, LR, Engsbro, AL, Stensvold, C R, et al, 2015: The prevalence of intestinal parasites is not greater among individuals with irritable bowel syndrome: a population-based casecontrol study. Clin. Gastroenterol. Hepatol. 13, 3:507-13.

Lu, CT, Sung, YJ, 2009: Epidemiology of Blastocystis hominis and other intestinal parasites among the immigrant population in northeastern Taiwan by routine physical examination for residence approval. J. Microbiol. Immunol. Infect. 42, 6:505-9.

Maizels, RM, Bundy, DA, Selkirk, ME, et al, 1993: Immunological modulation and evasion by helminth parasites in human populations. Nature 365, 6449:797.

Mohammad, KA, Koshak, EA, 2011: A prospective study on parasites among expatriate workers in Al-Baha from 2009-2011, Saudi Arabia. J. Egypt Soc. Parasitol. 41, 2:423-32. 
Mohammad, NA, Al-Mekhlafi, HM, Moktar, $\mathbf{N}$, et al, 2017: Prevalence and risk factors of $\mathrm{Bl}$ astocystis infection among underprivileged communities in rural Malaysia. Asian Pac. J. Trop. Med. 10, 5:491-7.

Nagel, R, Traub, RJ, Allcock, RJ, et al, 2016: Comparison of faecal microbiota in Blastocystispositive and Blastocystis-negative irritable bowel syndrome patients. Microbiome 4, 1:47-56.

Oishi, CY, Klisiowicz, DR, Seguí, R, et al, 2019: Reduced prevalence of soil-transmitted helminths \& high frequency of protozoan infectIons in the surrounding urban area of Curitiba, Paraná, Brazil. Parasit. Epidemiol. Con. 7:115-7. Pagheh, A, Sharif, M, Daryani, A, et al, 2018: A cross-sectional analysis of intestinal pa-rasitic infections among the general population in north of Iran. J. Infect. Dev. Ctries 12, 2:120-6.

Parkar, U, Traub, RJ, Vitali, S, et al, 2010: Molecular characterization of Blastocystis isolates from zoo animals and their animal-keepers. Vet. Parasitol. 169,1-2:8-17.

Pestehchian, N, Nazari, M, Haghighi, A, et al, 2015: Prevalence of intestinal parasitic infection among inhabitants and tribes of Chelgerd, Iran, 2008-2009. J. Clin. Diagn. Res. 9,5:1-4.

Popruk, S, Udonsom, R, Koompapong, K, et al, 2015: Subtype distribution of Blastocystis in Thai-Myanmar border, Thailand. Korean J. Parasitol. 53,1:13-9.

Poulsen, CS, Stensvold, CR, 2016: Systematic review on Endolimax nana: A less well studied intestinal ameba. Trop. Parasitol. 6,1:8-29.

Sahimin, N, Lim, Y, Ariffin, F, et al, 2016: Migrant workers in Malaysia: current implications of sociodemographic and environmental characteristics in transmission of intestinal parasitic infections. PLoS Negl. Trop. Dis. 10, 11:5110-27.

Salman, YJ, 2015: Detection of Blastocystis hominis among peoples in Kirkuk Province using ELISA and direct microscopy. Int. J. Curr. Microbiol. Appl. Sci. 4, 10:686-95.

Sánchez, A, Munoz, M, Gómez, N, et al, 2017: Molecular epidemiology of Giardia, Blastocystis and Cryptosporidium among indigenous children from the colombian amazon basin. Front Microbiol. 8:248-62.

Segui, R, Munoz-Antoli, C, Klisiowicz, DR, et al, 2018: Prevalence of intestinal parasites, with emphasis on the molecular epidemiology of Giardia duodenalis and Blastocystis sp., in the Paranagua Bay, Brazil: a community survey. Pa- rasit. Vectors. 11,1:490-509.

Silberman, J, Sogin, ML, Leipe, D, et al, 1996: Human parasite finds taxonomic home. Nature 380, 6573:398.

Srichaipon, N, Nuchprayoon, S, Charuchaibovorn, S, et al, 2019: A simple genotyping method for rapid differentiation of Blastocystis subtypes and subtype distribution of Blastocystis spp. in Thailand. Pathogens 8,1:38-63.

Stensvold, CR, 2013: Blastocystis: Genetic diversity and molecular methods for diagnosis and epidemiology. Trop. Parasitol. 3, 1:26-34.

Stensvold, CR, Arendrup, MC, Jespersgaard, C, et al, 2007: Detecting Blastocystis using parasitologic \& DNA-based methods: comparative study. Diag. Microbiol. Infect. Dis. 59, 3:303-7.

Taghipour, A, Azimi, T, Javanmard, E, et al, 2018: Immunocompromised patients with pulmonary tuberculosis; a susceptible group to intestinal parasites. Gastroenterol. Hepatol. Bed Bench. 11, 1:134-9.

Taha, HA, Soliman, MI, Banjar, SA, 2013: Intestinal parasitic infections among expatriate workers in Al-Madina Al-Munawarah, Kingdom of Saudi Arabia. Trop. Biomed. 30.1:78-88. Tan, KSW, Mirza, H, Teo, JDW, et al, 2010: Current views on the clinical relevance of Blastocystis spp. Curr. Infect. Dis. Rep. 12,1:28-35.

Uobeed, AH, Ali, GB, Mohammed, SK, 2015: Isolation and identification of Blastocystis hominis isolated from irritable bowel syndrome patients using phenotypic and genotypic methods. Int. J. Sci. Eng. Res. 6,11:1183-90.

van Lieshout, L, Roestenberg, M, 2015: Clinical consequences of new diagnostic tools for intestinal parasites. Clin. Microbiol. Infect. 21, 6: 520-8.

Wakid, H, 2009: Improvement of Ritchie technique by identifying the food that can be consumed preanalysis. J. Appl. Sci. Res. 5,3:293-6.

Wakid, MH, Azhar, EI, Zafar, TA, 2009: Intestinal parasitic infection among food handlers in the holy city of Makkah during Hajj season 1428 Hegira (2007G). KAUJ Med. Sci. 16, 1:39-52.

Yogyata, M, Binita, S, 2011: Prevalence of intestinal parasites at Ujjain, Madhya Pradesh, India: Five-year study. Afr. J. Microbiol. Res. 5, 18:2711-4.

Zhang, X, Qiao, J, Wu, X, et al, 2012: In vitro culture of Blastocystis hominis in three liquid media and its usefulness in the diagnosis of blas-tocystosis. Int. J. Infect. Dis. 16, 1:23-8. 